\title{
Transitional Cell Carcinoma of The ovary A Rare Case Report And Review of Literature.
}

\author{
Dr.Chandrahas Dhruw ${ }^{1}$ (MD), Dr. Manjula Kerketta ${ }^{1}$ (MD), Dr. Vikram Bali \\ Rathore $^{1}$ (Phd), Dr. Vivek Choudhary ${ }^{2}$ (MD), Dr. Surendra Kumar Azad ${ }^{3}$ (MD), \\ Dr. Pradeep Kumar Chandrakar ${ }^{1}$ (MD), Dr Rajeev Ratan Jain ${ }^{1}$ (MD),Dr.Neha \\ $\operatorname{khetan}^{4}(\mathrm{MD})$ \\ ${ }^{I}$ Assistant Professor, Department Of Radiotherapy, Regional Cancer Centre, Pt. J.N.M. Medical College, \\ Raipur, Chhattisgarh, India. \\ ${ }^{2}$ Professor And Head, Department Of Radiotherapy, Regional Cancer Centre, Pt. J.N.M. Medical College, \\ Raipur, Chhattisgarh, India. \\ ${ }^{3}$ Professor, Department Of Radiotherapy, Regional Cancer Centre, Pt. J.N.M. Medical College, Raipur, \\ Chhattisgarh, India. \\ ${ }^{4}$ Assistant Professor, Department Of Radio Diagnosis, Regional Cancer Centre, Pt. J.N.M. Medical College, \\ Raipur, Chhattisgarh, India.
}

\begin{abstract}
Transitional cell carcinoma of the ovary is a rare variant of epithelial ovarian cancers(EOC).It has been described as a primary ovarian carcinoma with definite urothelial features but no benign, metaplastic and/or proliferating Brenner tumor (BT) identified. Recognition of such tumors is important because of its rarity, favorable response to chemotherapy and an improved patient survival. Treatment comprised multimodality approach using surgery, chemotherapy and radiotherapy. Surgery remains the mainstay of the treatment of this variant of EOC. Postoperative adjuvant radiotherapy improved local control in patients with adverse prognostic factors. Adjuvant radiotherapy improves outcome in patients with adverse factors.
\end{abstract}

Keywords: Transitional cell carcinoma, EOC, Brenner Tumor, Treatment.

\section{Introduction}

Ovarian cancer is the most lethal gynecological malignancy. Efforts at early detection and new therapeutic approaches to reduce mortality have largely been unsuccessful, since the origin and pathogenesis of epithelial ovarian cancer are poorly understood (1). Transitional cell carcinoma (TCC), a recently recognized subtype, resembles urothelium rather than ovarian surface epithelium (methothelium) (2-3). A small percentage of ovarian cancer types are accounted for by TCC, which has proven to be a distinct group with various histological and immunohistological patterns. Patients with TCC had better prognoses compared to patients with all other types of ovarian carcinomas following standardized chemotherapy (4).TCC is classified along with benign, borderline and malignant Brenner tumor (5). It was first defined by Austin and Norris in 1987. In addition, TCC lacks the prominent stromal calcification.

\section{Case Report}

A 45 year old married woman with post hysterectomy status presented to cancer opd with the history of swelling over lower abdomen and pain over pelvis for 2 months. Pain over pelvic region was gradually progressive, dull aching, non-radiating type associated with off- on fever which was relieved after taking oral analgesics in the form of NSAIDS. On per abdominal examination a huge single nodular mass was felt over umbilical, left iliac, and hypogastric region which was deep seated, non-tender and ill-defined, skin over abdomen was glossy no puckering or dimpling were noted. There was no lymph node enlargements noted in bilateral inguinal region. On thorough per vaginal examination on lithotomy position upper vaginal wall and cervical os looked healthy. On per rectal examination bilateral parametrium were smooth. Her complete blood count, renal function tests, liver function tests, chest radiograph were within normal limits. Her contrast enhanced CT scan of whole abdomen and pelvis region (pretreatment) reveals a huge mass lesion involving umbilical, left iliac fossa and hypo gastric regions showing cystic as well as enhancing soft tissue components with calcifications measuring $14.0 * 16.4 * 9.8 \mathrm{cms}$. The lesion shows post contrast peripheral enhancement with few mildly enlarged pre and left Para aortic lymph nodes are noted measuring up to $10 \mathrm{~mm}$ in short axis s/o left ovarian neoplastic mass. On departmental meeting with multidisciplinary team. Patient was sent to oncosurgery unit. There she had undergone Bilateral Salpingo-oophorectomy(BSO) + Total Omentectomy on 18/03/16. Histopathology report of the specimen shows high grade transitional cell carcinoma of left ovary with tumor deposits on right ovary, sections from omentum shows metastatic deposits, both fallopian tubes were 
unremarkable. Further immunohistochemistry was performed which confirmed diagnosis as transitional cell carcinoma of ovary. Patient is now receiving chemotherapy injection Paclitaxel $260 \mathrm{mg}$ and injection Cisplatin $120 \mathrm{mg}$ in two divided doses every 3 weekly. Our treatment plan is to give 6 cycles of same chemotherapy every 3 weekly, and after 3 weeks of completion of chemotherapy, radiotherapy will be given to the tumor bed with 3DCRT technique to the dose of 50GY/25\#, over 5 weeks with appropriate beam energies in Linear Accelerator.

\subsection{Epidemiology}

\section{Review Of Literature}

The true incidence of TCC of the ovary remains unknown. Transitional cell tumors, including TCC, and benign and malignant Brenner tumors of the ovary represent $\sim 2 \%$ of all ovarian tumors. Moreover, according to the World Health Organization (WHO), depending on the histological pattern, these tumors are classified as benign, borderline or malignant Brenner tumors and TCC (6-7) the focal or diffuse TCC pattern in 88 of 934 ovarian cancers $(9 \%)$.

\subsection{Histopathology and Pathogenesis}

TCC of the ovary has close morphologic similarities to TCC of the bladder and it behaves more aggressively than malignant Brenner tumor, ovarian TCC arises directly from the pluripotential surface epithelium of the ovary and from cells with urothelial potential, rather than from a benign or proliferative Brenner tumor precursor. The clinical presentation is indistinguishable from other types of ovarian carcinoma(8).TCC of the ovary has been described as a primary high grade carcinoma in which definite urothelial features are present but no benign, metaplastic and/or proliferating Brenner tumor can be identified. The pure form of TCC accounts for only $1 \%$ of surface epithelial tumors, mixed carcinomas with a minor TCC component comprise $3 \%$ and those with a predominant TCC component make up $5 \%(7)$. These tumors have an immunohistochemical profile that is different from ovarian Brenner tumors and TCC involving the urinary tract. It has been proposed that ovarian TCC may represent a high grade serous carcinoma with morphologic features of transitional cell differentiation rather than being a distinct tumor type (9). Recognition of such tumors is important because of a favorable response to chemotherapy and an improved patient survival (10) Eichhorn and Young (11) found a variety of histologic features that, in aggregate, produced a distinctive appearance. The patterns included, in order of frequency; undulating, diffuse, insular, and trabecular. Punched out micro spaces, large cystic spaces, and large, blunt papillae were also common. The tumor cells tend to be relatively monomorphic with typically pale and granular cytoplasm, although occasionally it is clear or oxyphilic. The round to oblong nuclei has a large, single nucleolus or a longitudinal groove. Although nonspecific, slit-like fenestrations and bizarre tumor giant cells, two features of high-grade serous carcinoma, are frequently seen in TCC of the ovary (11). The immunoprofile of TCCs is similar to that of other surface epithelial carcinomas. Both Brenner tumor and ovarian TCC express CK7 but lack expression of CK 20 unlike urinary tract urothelial neoplasms. Most ovarian TCCs are immunoreactive for Wilms tumor protein (WT1) and, in contrast to Brenner tumors and extra ovarian urothelial tumors; they typically lack reactivity for uroplakin III and thrombomodulin. p63, another urothelial differentiation marker, has been demonstrated in benign and borderline Brenner tumors but not in ovarian TCC $(9,10$, and 12). Unlike bladder TCCs, ovarian TCCs are often positive for vimentin, CA-125 and WT (5).Almost all of the ovarian TCCs marked strongly for estrogen receptors (ERs) (13), a characteristic that may help to differentiate these lesions from papillary urothelial carcinoma metastatic to the ovary.

\subsection{Clinical Features}

The symptoms of TCC of ovary are indistinguishable with that of EOC and are non-specific too. Symptoms consists of progressively increasing lump in lower abdomen, mild to moderate colicky pelvic pain generally relieved by taking NSAIDS. In many cases, the preoperative diagnosis of TCC of ovary is extremely rare.

\subsection{Treatment}

Optimal surgical respectability comprising of Total Abdominal Hysterectomy with Bilateral Salpingooophorectomy and infracolic omentectomy and pelvic lymph node dissection is performed followed by Platinum and Taxolbased chemotherapy may contribute to the survival benefit (14-15).Advanced-stage ovarian TCC was significantly more chemosensitive and associated with better prognosis than poorly differentiated serous carcinoma (10). Patients with TCC had better prognoses compared to patients with all other types of ovarian carcinomas after standardized chemotherapy (16).Factors associated with survival for patients who received chemotherapy were the clinical stage, the percentage of the TCC component in the primary tumor and the results of second-look surgery. The predominance of TCC was a favorable prognostic factor and patients with higher clinical stages had poorer prognoses. 


\section{Conclusion}

Transitional cell carcinoma (TCC) of the ovary is a rare subtype of epithelial ovarian cancer. Surgical resection is the primary therapeutic approach, and patient outcomes after chemotherapy are better than for other types of ovarian cancer.

\section{Acknowledgements}

The authors would like to thanks Dr.A.K.Chandrakar, Dean, Pt.J.N.M.Medical College,Raipur for his continuous encouragement and support for this study.

\section{References}

[1]. Kumar R, Shih I-M. The Origin And Pathogenesis Of Epithelial Ovarian Cancer: A Proposed Unifying Theory. Am J Surgpathol. 2010;34:433-443.

[2]. Cuatrecasas M, Catasus L, Palacios J, Prat J. Transitional Cell Tumors Of The Ovary: A Comparative Clinicopathologic, Immunohistochemical, And Molecular Genetic Analysis Of Brenner Tumors And Transitional Cell Carcinomas. Am J Surgpathol. 2009;33:556-567.

[3]. Oh S, Rha S, Jung S, Lee Y, Choi B, Byun J, Ku Y, Jung C. Transitional Cell Tumor Of The Ovary: Computed Tomographic And Magnetic Resonance Imaging Features With Pathological Correlation. J Comput Assist Tomogr. 2009;33:106-112.

[4]. Kommoss F, Kommoss S, Schmidt D, Trunk M, Pfisterer J, Du Bois A. Survival Benefit For Patients With Advanced-Stage Transitional Cell Carcinomas Vs. Other Subtypes Of Ovarian Carcinoma After Chemotherapy With Platinum And Paclitaxel. Gynecoloncol. 2005;97:195-199.

[5]. Lee Kr, Tavassolifa, Prat J, Et Al. Tumors Of The Ovary And Peritoneum. In: Tavassolifa, Devilee P, Eds. World Health Organization Classification Oftumours. Pathology And Genetics Of Tumours Of The Breast And Female Genital Organs.Lyon: Iarc Press. 2003:113-45.

[6]. World Health Organization. Classification Oftumours: Pathology And Genetics Of Tumors Of The Breast And Female Genital Organs.Iarc Press; Lyon: 2003. Pp. 140-143.

[7]. Silva E, Robey-Cafferty S, Smith T, Gershenson D. Ovarian Carcinomas With Transitional Cell Carcinoma Pattern. Am J Clinpathol. 1990;93:457-465.

[8]. Austin Rm, Norris Hj. Malignant Brenner Tumor And Transitional Cell Carcinoma Of The Ovary: A Comparison. Int J Gynecolpathol. 1987;6: 29-39

[9]. Ali Rh, Seidmanjd, Luk M, Kalloger S, Gilkscb. Transitional Cell Carcinoma Of The Ovary Is Related To High-Grade Serous Carcinoma And Is Distinct From Malignant Brenner Tumor. Intj Gynecolpathol. 2012 Nov;31(6): 499-506.

[10]. Gershensondm, Silva Eg, Mitchell Mf, Atkinson En, Wharton Jt. Transitional Cell Carcinoma Of The Ovary: A Matched Control Study Of Advanced-Stage Patients Treated With Cisplatin Based Chemotherapy. Am J Obstet Gynecol. 1993;168: 1178-85.

[11]. Eichhornjh, Young Rh. Transitional Cell Carcinoma Of The Ovary. A Morphologic Study Of 100 Cases With Emphasis On Differential Diagnosis. Am J Surgpathol. 2004;28: 453-63.

[12]. Logani S, Oliva E, Amin Mb, Folpe Al, Cohen C, Young Rh. Immunoprofile Of Ovarian Tumors With Putative Transitional Cell (Urothelial) Differentiation Using Novel Urothelial Markers: Histogenic And Diagnostic Implications. Am J Surgpathol. 2003;27: 1434-41.

[13]. Croft Pr, Lathrop S1, Feddersenrm, Joste Ne. Estrogen Receptor Expression In Papillary Urothelial Carcinoma Of The Bladder And Ovarian Transitional Cell Carcinoma. Arch Pathol Lab Med. 2005;129: 194-99.

[14]. Tazi E, Lalya I, Tazi M, Ahellal Y, M'rabti H, Errihani H. Transitional Cell Carcinoma Of The Ovary: A Rare Case And Review Of Literature. World J Surgoncol.2010;8:98-101.

[15]. Lin C, Liu F, Ho E. Transitional Cell Carcinoma Of The Ovary. Taiwan J Obstet Gynecol. 2006;45:268-271 .

[16]. Kommoss F, Kommoss S, Schmidt D, Trunk Mj, Pfisterer J, Du Bois A, Arbeitsgemeinschaftgynaekologischeonkologiestudiengruppeovarialkarzinom: Survival Benefit For Patients With Advanced-Stage Transitional Cell Carcinomas Vs. Other Subtypes Of Ovarian Carcinoma After Chemotherapy With Platinum And Paclitaxel.Gynecoloncol 2005, 97:195-9.

Figures

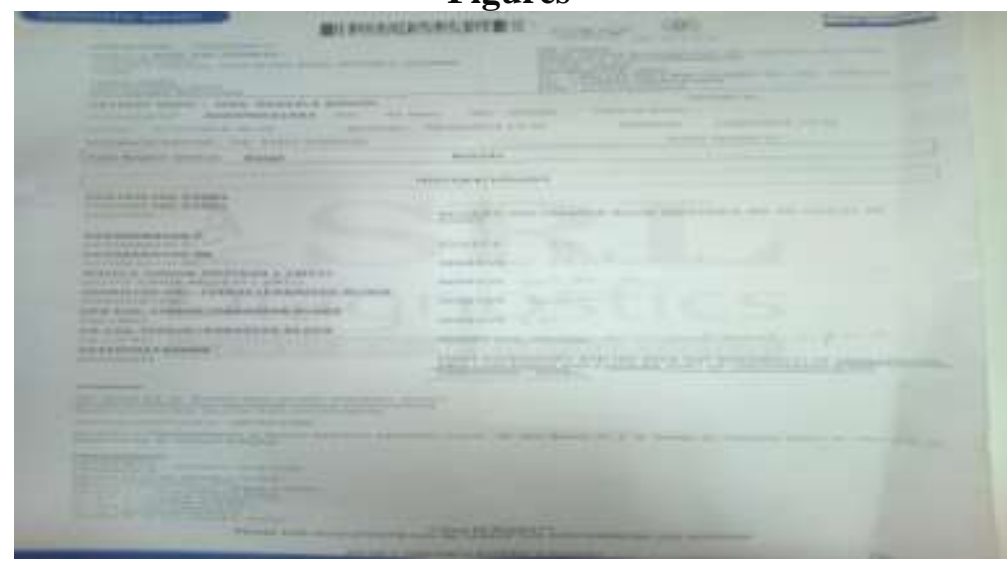

Figure 1.2 


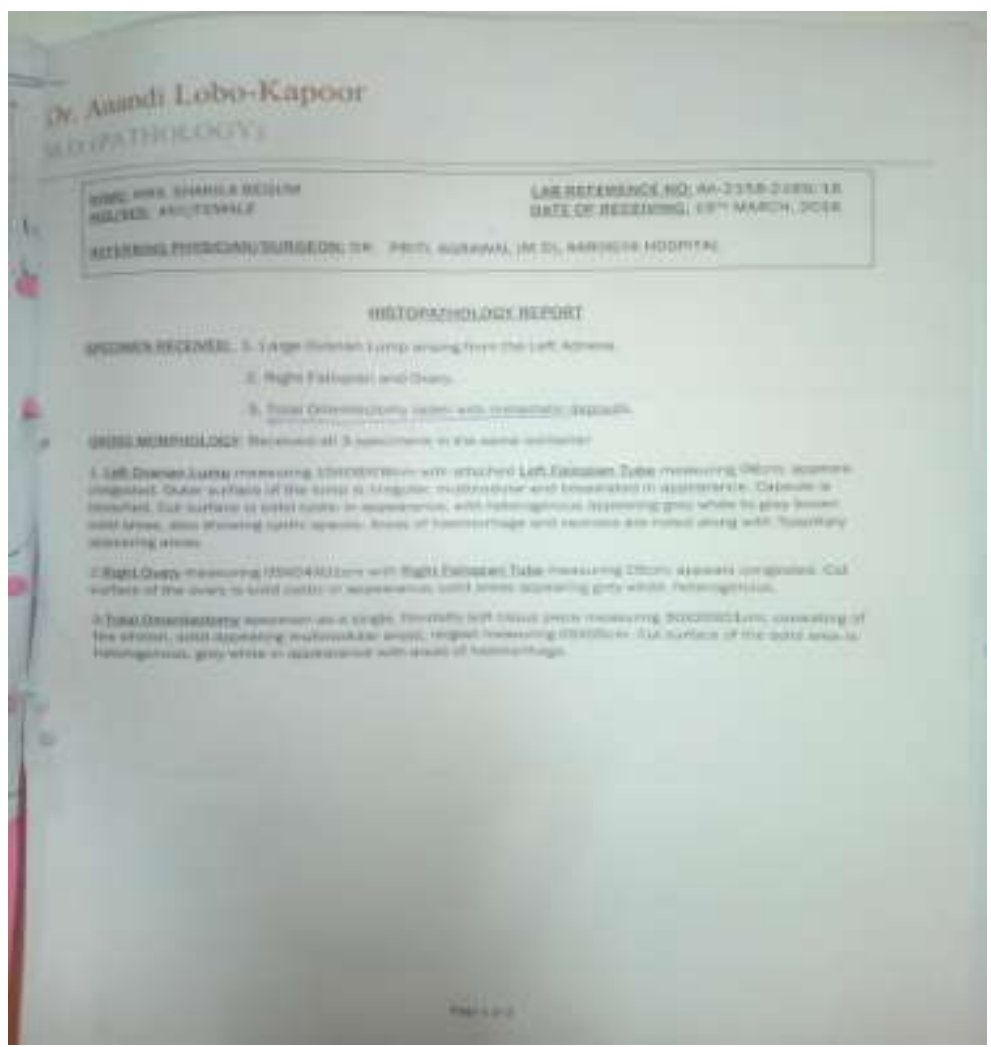

Figure 1.3

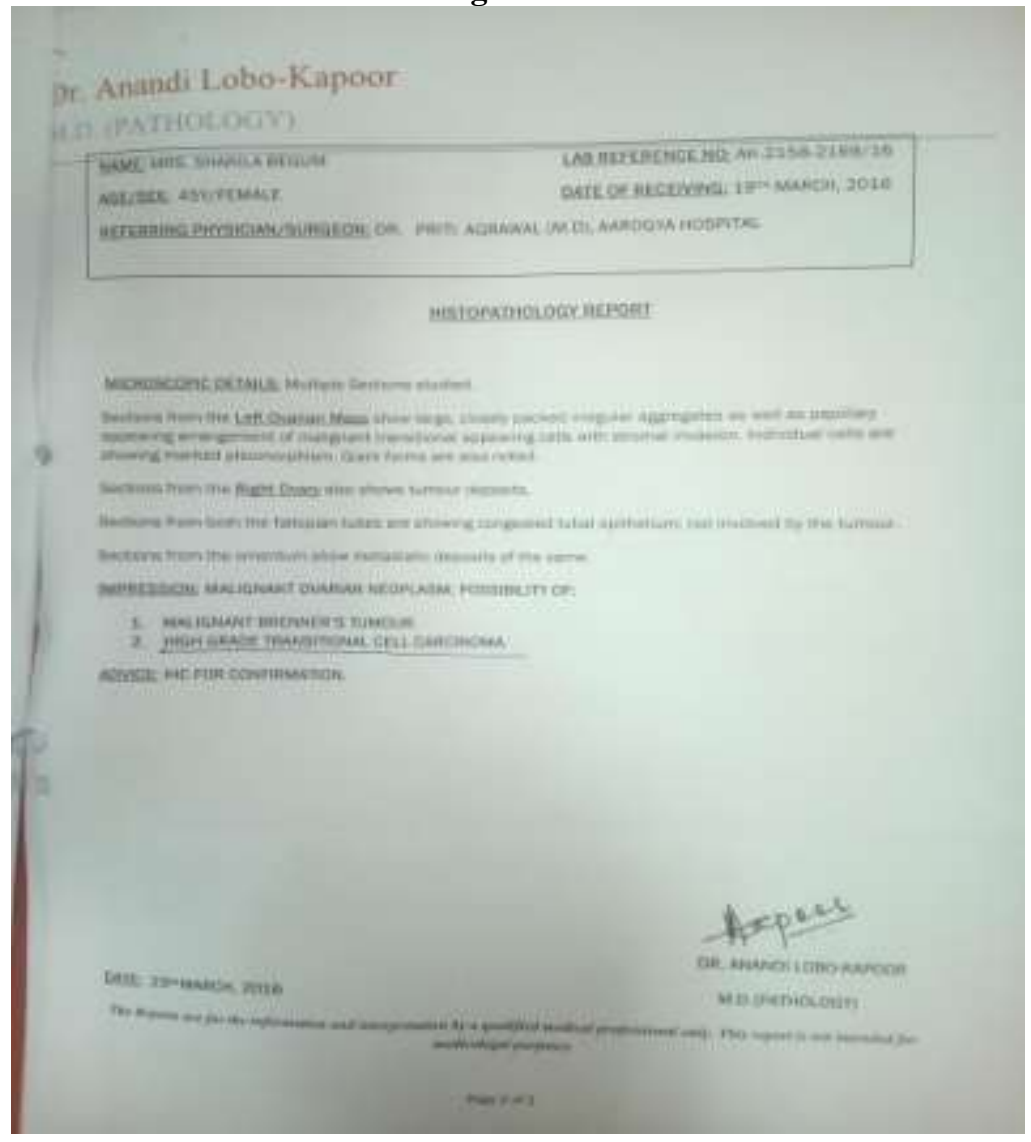

